\title{
Improving the shape quality of bearing rings in soft turning by using a Fast Tool Servo
}

\author{
Björn L. T. Beekhuis • Ekkard Brinksmeier • \\ Martin Garbrecht $\cdot$ Jens Sölter
}

Received: 6 May 2009/ Accepted: 4 September 2009/Published online: 10 October 2009

(C) The Author(s) 2009. This article is published with open access at Springerlink.com

\begin{abstract}
In machining of ring shaped components, the workpiece is deformed by the clamping forces of the chuck. This elastic deformation generates shape deviations in soft turning. Moreover, the machining process generates locally varying residual stresses which contribute to shape deviation of the workpiece. Hence, in machining of thinwalled bearing rings hexagonal out-of-roundness up to $200 \mu \mathrm{m}$ occur. In order to minimize the shape deviations, a long stroke Fast Tool Servo (FTS) for controlling the depth of cut was developed. The applied FTS differs from other published FTS systems in the guidance design. The moving tool holder is suspended to the FTS frame by flexure joints instead of using a linear guidance. The flexure joints provide a low stiffness in moving direction and high stiffness in orthogonal directions. The high stiffness in cutting force direction is essential for a real time reduction of shape deviations in soft turning. In this paper, results of an experimental investigation for the reduction of the shape deviation by adapted non circular machining are presented, using the developed FTS. Based on the results, the influence of the cutting forces on part accuracy is discussed.
\end{abstract}

Keywords Soft machining - Shape deviation . Tool actuator $\cdot$ Bearing rings $\cdot$ Noncircular machining . Distortion

B. L. T. Beekhuis $(\bowtie) \cdot$ E. Brinksmeier · M. Garbrecht · J. Sölter

IWT Bremen, Bremen, Germany

e-mail: Beekhuis@iwt-bremen.de

\section{Introduction}

The shape deviation of thin-walled cylindrical rings increases in soft turning. This provokes high grinding allowances after turning and subsequent heat treatment. Therefore, a reduction of a subsequent form correction by expensive hard-machining offers a high cost saving potential.

Three main effects have been discussed by corresponding literature, when analyzing soft machined workpieces with respect to shape deviation:

- elastic deformation due to clamping forces,

- cutting forces, and

- residual stresses induced by the machining process.

The main effect with respect to shape deviation is the deformation of workpieces due to clamping, e.g. by a three jaw chuck on a lathe (Fig. 1). Circular machining of such deformed rings results in a varying circumferential wall thickness. After releasing the rings, shape deviations of the outer and inner ring surfaces occur. For analyzing these shape deviations, the Fast Fourrier Transformation (FFT) method can be used, as Surm has described in [1]. E.g. the clamping of rings by a three jaw chuck increases the third order of FFT. This third order is synonymous with the triangularity of the rings.

The effects of clamping techniques on deformations of thin walled rings have been investigated by many researchers. As it is shown in the work of Wagner [2], Rahmann [3] and Tönshoff [4], the amount of the elastic deformation due to clamping depends on the hydraulic pressure of the clamping system, the moment of inertia of the workpiece and additionally the contact stiffness between chuck and workpiece. Other papers of Weinert [5] and Spur [6] describe that the elastic deformation of 


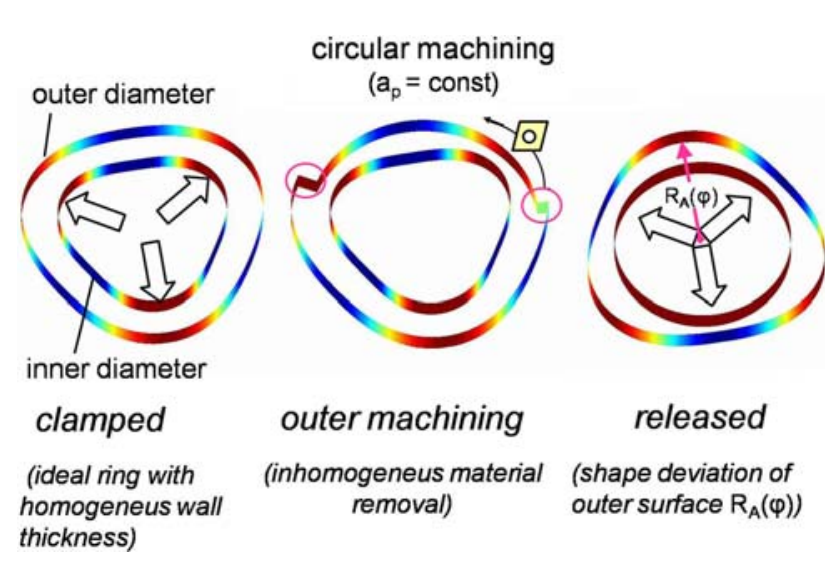

Fig. 1 Shape deviation of the outer surface due to inhomogeneous material removal in circular machining of deformed rings

thin-walled workpieces is also influenced by the cutting forces.

Finally, an important effect with respect to shape deviation is the change of shape due to varying residual stresses. This can be explained by the generation of a surface layer of plastically deformed material in soft turning, as investigated by Tönshoff et al. [7, 8]. In the work of Brinksmeier et al. $[9,10]$ it was shown, that the resulting residual stresses in the surface layer varies locally after turning. From those circumferential varying inhomogeneous residual stresses results a change of the shape after turning and a subsequent heat treatment process, as discussed by Surm [1] and Volkmuth [11].

By considering the mentioned mechanisms, and by analyzing the corresponding literature, several methods are possible to reduce shape deviations in turning. Generally, they can be summarized by two approaches:

- reduction of workpiece deformation due to clamping, and

- adapted noncircular machining.

The easiest way to minimize deformations due to clamping is to increase the clamping area. So, numerous form adapted special clamping devices like clamping sleeves are applied in industry. Some of them are described in [12]. However, when choosing a clamping technique the effectiveness of the turning process has to be considered. In low volume production, for example the flexibility of a machining system is important. In these cases standard clamping systems like three jaw chucks are commonly used.

The other promising approach for the reduction of shape deviations is noncircular machining, which is well known for its excellent flexibility and precision. In noncircular machining the cutting tool is driven by a Fast Tool Servo (FTS). The dynamic back and forth motion of the FTS is superimposed to the nominal motion of the corresponding
CNC controlled axis of the lathe. The range of application of a FTS is wide. E.g. surfaces of engine pistons [13], mirrors [14, 15] and lenses [16] are noncircularly finished. The corresponding literature confirms that the applied FTS have either a high dynamic range with low retention forces or long stroke and low dynamic range. For example the applied Ultra FTS for machining of optical quality surfaces by noncircular machining in [17] is driven by piezoelectric actuators. In this case, the use of piezoelectric elements allows a very high frequency of motion and also a high accuracy, but only low cutting forces and a limited displacement.

However, because of the self contradictory requirements a FTS has to be designed for its application. For example in machining of thin walled bearing rings hexagonal out-ofroundness up to 200 microns occurs. So far, no FTS was known that fulfills these requirements for real-time shape correction in soft turning of bearing rings. Hence, a new long stroke FTS was developed (Fig. 2). The fundamental design of the FTS and the experimental setup is described in Chap. 2.

\section{Objectives and experimental procedure}

\subsection{Objectives}

For the first time noncircular machining of thin walled bearing rings with high shape deviations was conducted using the integrated FTS. The objective was to minimize the shape deviation of the outer surface by adapting the depth of cut. In order to demonstrate the performance of this method, the wall thickness of the machined workpieces was varied.

\subsection{Applied Fast Tool Servo}

Basic characteristics of the applied FTS are summarized in Table 1. Further details were published by Dijkman [18] and Stoebener [19]. A particular design feature of the FTS is that the moving tool holder is suspended to the FTS frame by a flexure bearing instead of using linear guiding (Fig. 2). Due to the resulting oscillation of this design the stroke is limited up to $300 \mu \mathrm{m}$ in order to guarantee a low tracking error in linear feed direction. An approach for real time shape correction with the FTS described above was developed by Dijkman [17] and Stoebener [19]. They presented a design of the controller, which is suitable for real-time controlling of depth of cut. For the described experiments within this work a real-time measurement was not available. Hence, the calculation of the cutting tool track was based on in-situ geometric measurements of the rings in the lathe before the finishing cut (Fig. 3). 
Fig. 2 Long stroke Fast Tool Servo for real time noncircular machining of thin-walled bearing rings
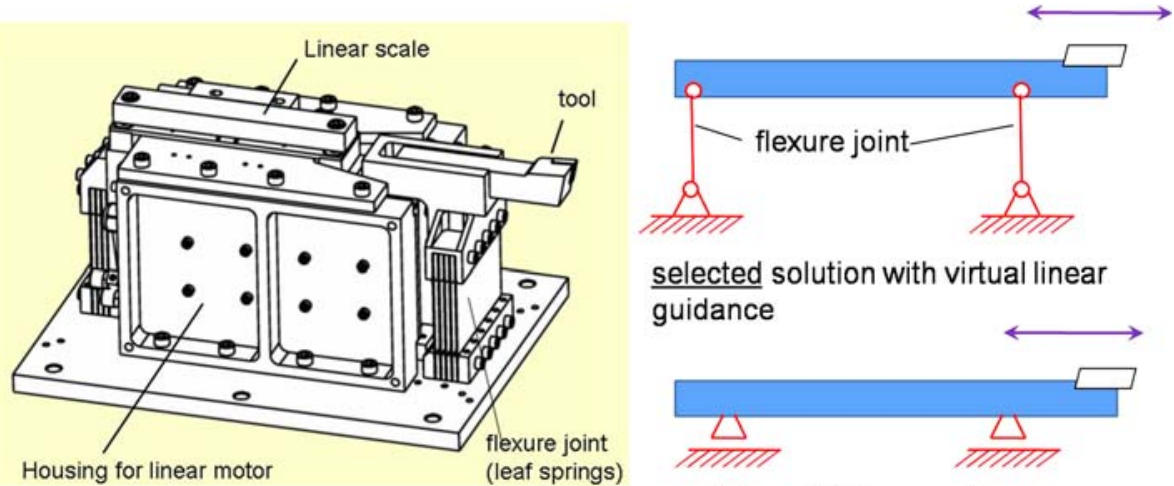

selected solution with virtual linear guidance

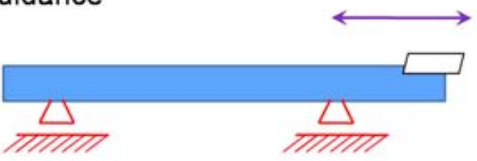

solution with linear guidance
Table 1 Technical data of the applied FTS

\begin{tabular}{ll}
\hline Maximal feeding path & $\pm 300 \mu \mathrm{m}$ \\
Dynamic range & $0.60 \mathrm{~Hz}$ \\
Maximal retention force & $1,000 \mathrm{~N}$ \\
Response time & $1 \mathrm{~ms}$ \\
Max. workpiece speed & $600 \mathrm{rpm}$ \\
Weight & $60 \mathrm{~kg}$ \\
Dimensions & $0.4 \mathrm{~m} \times 0.5 \mathrm{~m} \times 0.35 \mathrm{~m}$ \\
\hline
\end{tabular}

\subsection{Experimental setup}

Figure 4 shows the experimental setup. The machining system consists of two parts; a CNC lathe and the FTS.

The applied vertical turning center with counter spindle is common for turning parts in medium to large quantities. Hence, such systems are often used for machining bearing rings.

The FTS generates a tool motion in the radial cutting direction. In addition to the dynamic back and forth motion of the FTS a nominal depth of cut is superimposed by the CNC controlled $X$-axis of lathe (Figure 4). Thus the depth of cut varies depending on the angular position of the workpiece. Further details regarding the synchronization of the machine spindle with the FTS motion are described in [18].

\subsection{Experimental procedure}

In summary, the experiments comprise three different states of the workpieces (Fig. 5):

state 1: parts with shape deviation due to circular machining,

state 2: parts with reduced shape deviation of outer surface after FTS machining, and

state 3: parts with change of shape deviation due to heat treatment.

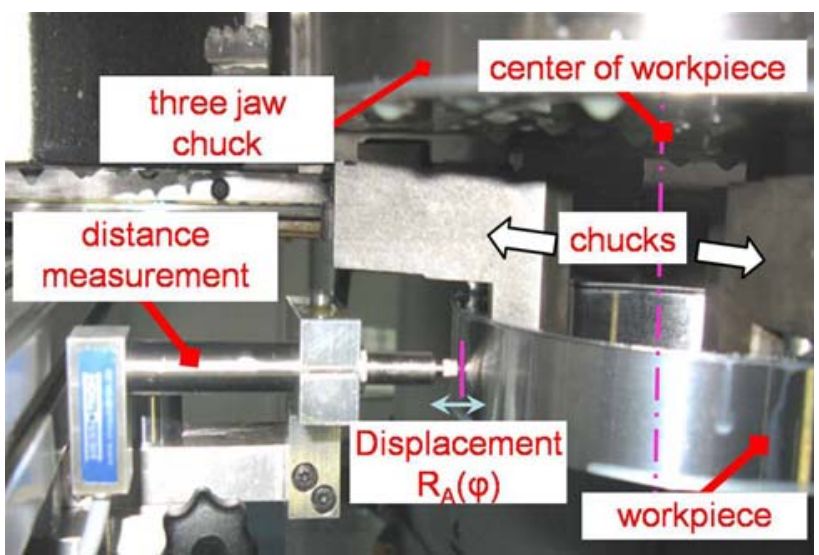

Fig. 3 Measuring setup in lathe for shape measurement

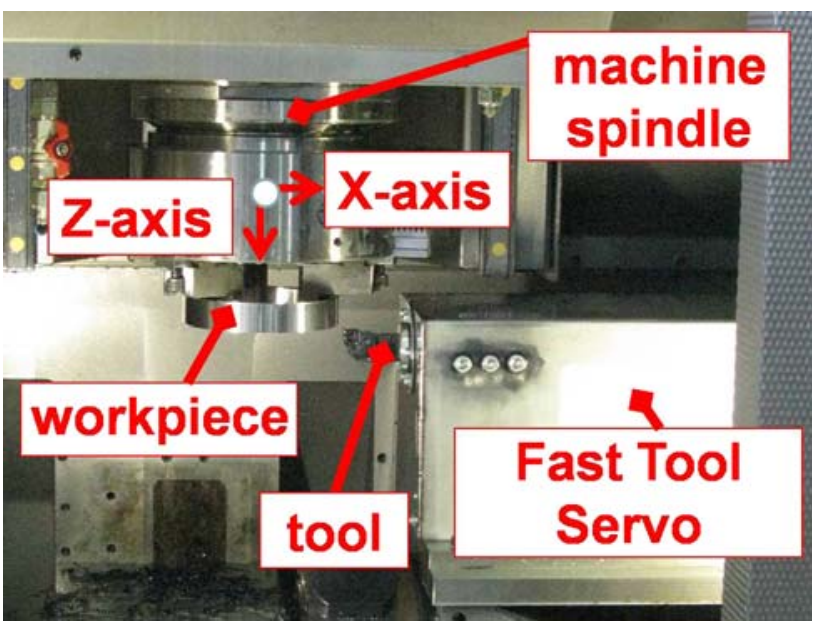

Fig. 4 Machining system in a vertical turning center

The steel rings were initially sawn from a hot rolled and stress relief annealed tube made of SAE 52100 (100Cr6). The inner and outer surfaces were circular pre-machined using a three-jaw-chuck in order to generate surface shape deviations. The nominal inner diameter $\left(D_{\mathrm{I}}=133 \mathrm{~mm}\right)$ and the width $(b=26 \mathrm{~mm})$ were kept constant. The outer 


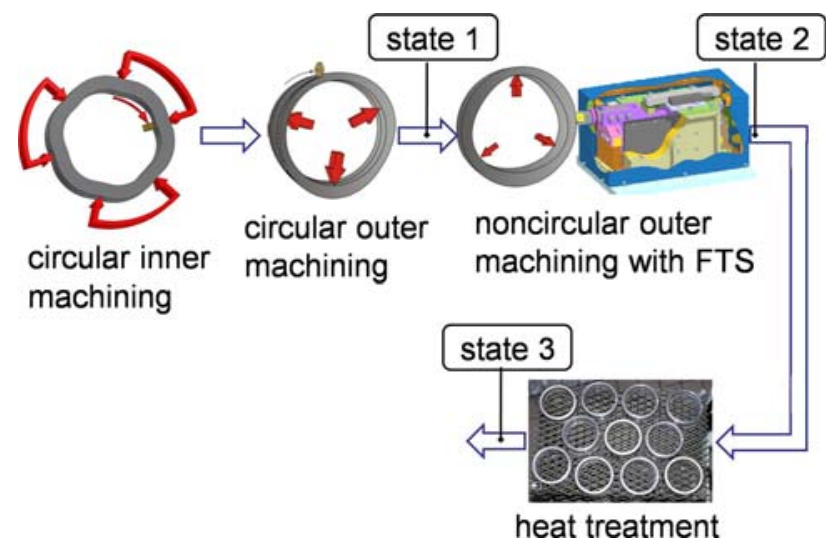

Fig. 5 Experimental procedure and conditions of rings

Table 2 Parameter setting for the turning experiments

\begin{tabular}{llllll}
\hline$\gamma_{\text {eff }}\left({ }^{\circ}\right)$ & $\alpha_{\text {eff }}\left({ }^{\circ}\right)$ & $\lambda\left(^{\circ}\right)$ & $\kappa\left(^{\circ}\right)$ & $\nu_{\mathrm{c}}(\mathrm{m} / \mathrm{min})$ & $f(\mathrm{~mm})$ \\
\hline 14 & 6 & -6 & 95 & 240 & 0.3 \\
\hline
\end{tabular}

diameter varied in order to machine rings with different wall thicknesses.

After pre-machining the shape deviations and the elastic deformation were measured at the center path of each ring (Fig. 3).

The main experiment consisted of one longitudinal noncircular cut on the exterior of the rings in order to minimize the shape deviation. The average depth of cut was $a_{\mathrm{p} \text {,eff }}=0.25 \mathrm{~mm}$. Cemented carbide tools CNMG 160608 with a TiN-coating were used for noncircular machining. The tool setting conditions and the machining parameters are listed in Table 2.

The trajectory of the cutting tool was calculated based on previous geometry measurements. The influence of shape change due to residual stresses and cutting forces were neglected. The reduction of shape deviation was calculated after shape measurement of the noncircular machined outer ring surface.

In order to evaluate the error caused by neglecting the shape change due to residual stresses, a stress relief annealing was carried out after the tuning experiments. In addition, residual surface stresses were measured by $X$-ray diffraction before stress relief annealing, in order to determine the amount of inhomogeneous residual stresses generated by a varying depth of cut during noncircular machining.

\section{Results}

The shape deviation after pre-machining increases as wall thickness decreases (Fig. 6). It can be assumed that the

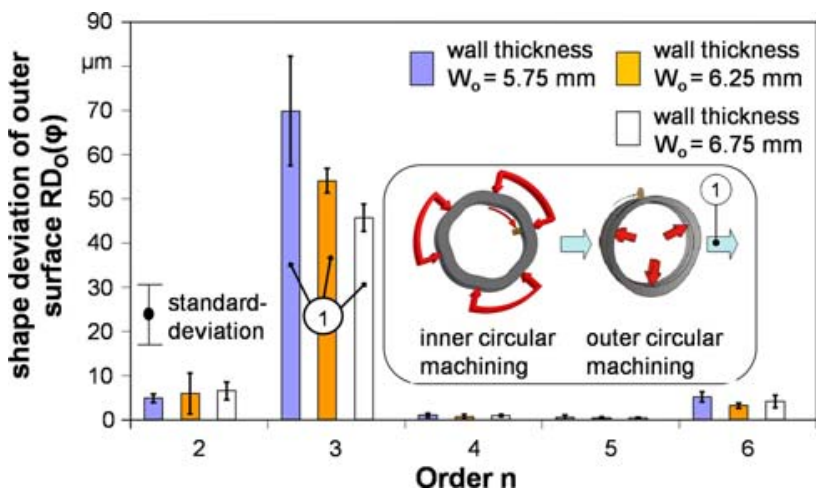

Fig. 6 Radial deviation of outer surface after pre-machining the rings

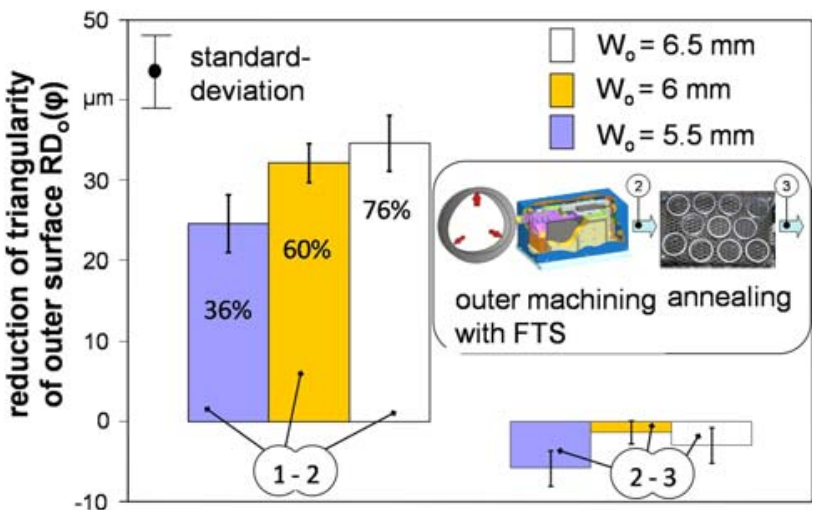

Fig. 7 Reduction of dominant triangularity after adapted noncircular machining and subsequent stress relief annealing

shape deviation due to the elastic deformation of the rings increases with decreasing moment of inertia at constant clamping forces. After releasing the rings, the outer surfaces show an oval, triangular and hexagonal shape deviation. It is obvious that the triangularity dominates the shape deviations in all three groups of rings. Hence, the following analysis of shape deviation focuses on changes of the triangularity.

Accordingly it is shown in Fig. 7 that the triangular shape deviation of the outer surface could be reduced by noncircular machining by using the FTS.

It became obvious that the compensation effect of the noncircular cutting decreases as wall thickness decreases. Thus the triangular shape deviation of rings with maximal wall thickness is reduced by $76 \%$, however the shape deviation of the class with minimal wall thickness was reduced by $36 \%$. For this decreasing compensation ability three reasons can be assumed:

- tracking error,

- shape change due to change of residual stress state by machining, and

- neglecting ring deformation due to cutting forces. 
Regarding the tracking error it has to be considered that the stroke of the FTS depends on the shape deviation of rings after pre-machining. Hence, the stroke increases as wall thickness decreases. Subsequently, it can be assumed that the tracking error of the FTS increases as stroke increases. For the determination of the tracking error trial cuts have been conducted after turning experiments. Results of similar trial cuts have been published in previous investigation by Dijkman [18]. It became clear that the tracking error alone is not responsible for such drop of compensation performance.

It can be assumed that the drop of the compensation ability might be caused by neglecting the influence of the residual stresses. Therefore the change of shape due to residual stresses was measured by comparing the shape deviation before and after stress relief annealing. It became obvious that the shape deviation increases after stress relief annealing. The change of shape between state two (shape deviation minimized) and state three (stress relief annealing) is shown in Fig. 7. The change is relative small and therefore cannot be responsible for the drop of compensation ability. In addition the tangential residual stresses were measured before heat treatment, because the results of tangential stress measurements after noncircular machining of bearing rings were not known a priori. The measured stress levels are also an indicator for shape changes due to annealing. It can be noticed that the dynamically adapted cutting process generated locally varying residual stresses in the surface layer (Fig. 8).

Thus, the final possible reason for the drop of compensation ability to be discussed is the influence of cutting forces. It can be assumed, that the cutting forces deform the ring during noncircular machining. Accordingly the change of deformation of the workpiece due to cutting force would be responsible for the drop of ability of the noncircular machining. Even if the tracking error is low, the depth of cut could not be achieved as the ring deformation was changed.

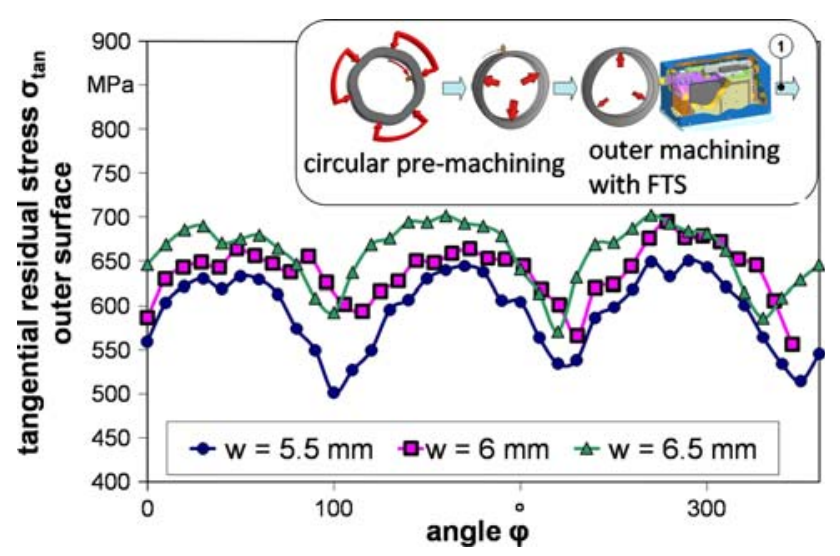

Fig. 8 Tangential residual stresses of the outer surface after dynamically adapted cutting
In order to investigate whether the passive force could be responsible for the drop of compensation ability, clamping simulations were conducted with the FE software SYSWELD. The hereby used geometric ring model was defined by the ring geometry prior to the last cut according to the experimental cutting sequence of the thinnest ring $\left(D_{\mathrm{I}}=133 \mathrm{~mm}, D_{\mathrm{A}}=145.5 \mathrm{~mm}, b=26 \mathrm{~mm}\right)$. For the simulation an elastic material behavior with an elastic modulus of $E=212 \mathrm{GPa}$ and a Poisson number of $v=0.283$ was assumed. Within this calculation the local plastic deformation of the surface of the ring due to clamping forces was neglected.

Furthermore the total clamping force of $F_{\mathrm{cl}}=18,500 \mathrm{~N}$ was assumed to be equally distributed over the clamping positions and was applied to the nodes (Fig. 9) of a 3D FE model. By these three different static simulations an assumed passive force $F_{\mathrm{p}}=400 \mathrm{~N}$ was applied to nodes belonging to circumferential angles $\phi=30,60$, and $90^{\circ}$. For each angle 3 different positions of the passive force over the ring width $(0,6.5$, and $13 \mathrm{~mm})$ were taken into account. Including the deformation state of the ring without passive forces a total of 10 simulations were conducted.

Radial displacements in the clamped state were computed from the simulation results. In order to evaluate the influence of the passive force on ring deformation the change of the radial deviation from the state without a passive force to a state including it was calculated for the concerned nodes (Fig. 10).

The results of the simulation show that the influence of the passive force is significant. The ring with the lowest moment of inertia is considerably deformed due to the passive force. Hence the adapted depth of cut cannot be achieved in noncircular machining. A reason for this could be that the material removal is too low. Therefore it has to be ensured that the trajectory of cutting tool track compensates the deformation caused by the cutting forces. Accordingly, the controller of the applied FTS has to be adjusted. This can be achieved by a neural network, which controls the trajectory of the tool track. This network could

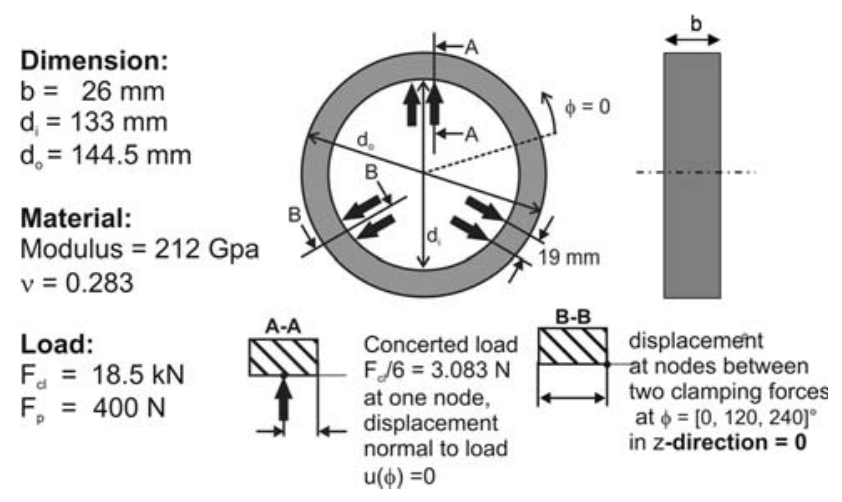

Fig. 9 Model for an estimation of shape changes due to passive forces 


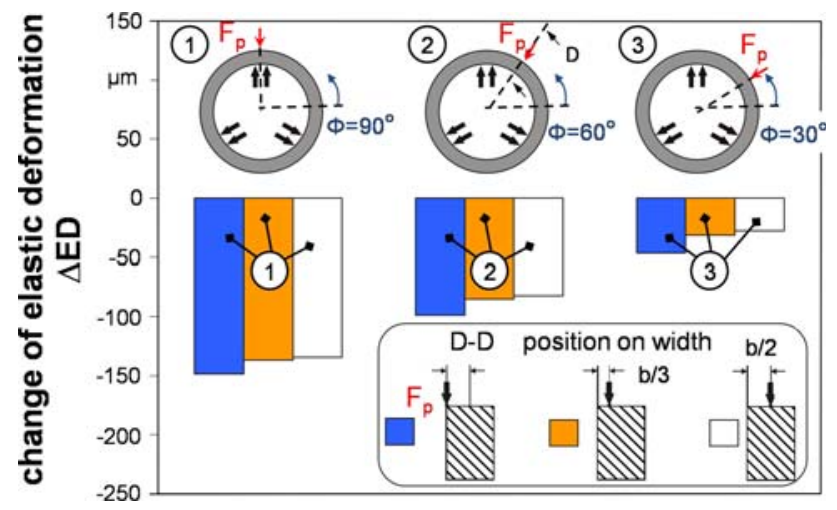

Fig. 10 Calculated changes of ring deformation due to passive forces

be trained with the results of the simulation to estimate the ring deformation due to the cutting force.

Another way to adjust the trajectory could be the control of the retention force of the actuator, which is proportional to the passive force. According to the relation of Kienzle [20] the depth of cut could be controlled by controlling the cutting forces. Therefore, within further work it has to be investigated if a control of the retention forces can decrease the identified influence of the passive force on the shape deviation.

\section{Conclusions}

The shape deviations of thin-walled bearing rings increase during turning. In this paper, it has been shown that the deviation can be reduced by noncircular machining with a FTS. The ability to reduce the shape deviation during noncircular cutting decreases as the moment of inertia of workpiece decreases. In addition to this experimental work, simulation were carried out to investigate the influence of the cutting forces on the change of deformation during noncircular cutting. The results of the simulations confirm that the ring deformation is influenced considerably in machining by cutting forces. Hence, the desired material removal cannot be achieved precisely without taking this effect into account. Hence, the controller of the FTS has to be adjusted. One possibility would be to use a neuronal network in order to estimate the deformation and adjust the trajectory of cutting tool track in order to increase the performance of the applied noncircular cutting.

Acknowledgments The authors would like to thank the Deutsche Forschungsgemeinschaft (DFG) for the financial support of this work within the SFB 570 "Distortion Engineering".

Open Access This article is distributed under the terms of the Creative Commons Attribution Noncommercial License which permits any noncommercial use, distribution, and reproduction in any medium, provided the original author(s) and source are credited.

\section{References}

1. Surm H, Keßler O, Frerichs F, Hoffmann F, Zoch H-W (2008) Erweiterte Verzugsanalyse am Beispiel von Wälzlagerringen.Dem Verzug eine Richtung geben! HTM Zeitschrift für Werkstoffe Wärmebehandlung Fertigung 63(2):95-103

2. Wagner HD (1987) Spannkraftverluste beim Drehen unter Beachtung der radialen Verformung und Steifigkeit von Werkstücken. Dr.-Ing. Thesis, TU Darmstadt, Carl Hanser Verlag, München, Wien

3. Rahman M (1985) Effect of clamping conditions on chatter stability and machining accuracy. Ann CIRP 34(1):339-326

4. Tönshoff HK, Noske H (1990) Machine tool monitoring apllied to Lathe Chucks. Ann CIRP 39(1):429-342

5. Weinert K, Peters C, Schulte M (2002) Simulation der spanenden Bearbeitung dünnwandiger Profile. ZWF 97(12):649-651

6. Spur G, Mette U (1998) Gripping-force optimization for highspeed turning. In: Proceedings of the international seminar on improving machine tool performance. San Sebastian, 1:151-160

7. Tönshoff HK (1966) Eigenspannungen und plastische Verformung im Werkstück durch spanende Bearbeitung. Dr. Ing. Thesis, Universität Hannover

8. Brinksmeier E, Cammet JT, König W, Leskovar P, Peters J, Tönshoff HK (2000) Residual stress-measurement and causes in machining processes. Ann CIRP 31(2):491-510

9. Nowag L, Sölter J, Walter A, Brinksmeier E (2005) Effect of machining parameters and clamping technique on residual stresses and distortion of bearing rings. In: Proceedings of the 1st international conference on distortion engineering. Bremen, pp 185-193

10. Brinksmeier E, Sölter J, Grote C (2007) Distortion engineeringidentification of causes for dimensional and form deviations of bearing rings. Ann CIRP 56(1):109-112

11. Volkmuth J, Sjöblom U, Slycke J, Thuvander A (2000) Effect of Uneven residual stresses on dimensional changes and variations of through hardening of bearing steel rings. In: Proceedings of the ASM heat treating society conference. St. Louis, pp 455-460

12. Basile A (2008) Sicheres deformationsarmes Spannen beim Drehen dünnwandiger Hohlteile. MM Das Industrie Magazin 36:94-97

13. Tsao TC, Tomizuka M (1994) Robost adaptive and repitive digital control and aplication to a hydralic servo for noncircular machining. Trans ASME 116:24-32

14. Cuttino JF, Miller AC, Schinstock DE (1999) Performance optimization of a fast tool servo for single-point diamond turning machines. Trans ASME 4:169-179

15. Klocke F, Weck M, Fischer S, Özmeral H, Schroeter RB, Zamel S (1996) Ultrapräzisionsbearbeitung und Fertigung von Mikrokomponenten. Industrie Diamenten Rundschau 23(3):172-177

16. Ludwick JS, Chargin DA, Calzaretta JA, Trumper DL (1999) Design of rotary fast tool servo for ophthalmic lens fabrication. Precis Eng 23:253-259

17. Lu X-D, Trumper DL (2005) Ultrafast tool servos for diamond turning. Ann CIRP 54(1):383-388

18. Dijkman M, Stobener D, Allers S, Kuhfuss B, Goch G (2007) Inprocess control of cutting depth during turning. In: Proceedings of the SICE annual conference., Kagawa, pp 2984-2989

19. Stoebener D, Dijkman M (2007) An ultrasound in-process-measuring system to ensure a minimum roundness deviation for rings during turning. Ann CIRP 56

20. Kienzle O (1952) Die Bestimmung von Kräften und Leistungen an spanenden Werkzeugen und Werkzeugmaschinen. VDI-Z Jg. 94 H. 11/12:299-305 